$10^{4}$ to $10^{5} \mathrm{rad} / \mathrm{h}$ range. A difference between the action of $\gamma$-rays and electrons on the shrinkage temperature of catgut was noted by Schnell et al. (page 145). The abolition of antigenicity in bone for grafting when sterilized by $\gamma$-rays was also reported whereas with larval and bacterial vaccines the effect on antigenicity was slight at a dose sufficient to sterilize.

A comparison between radiosterilization and ethylene oxide sterilization is made in a paper by Brewer and the lengthy discussion this promoted is given in full. The six final papers on technical and economic aspects will be of special interest to those interested in setting up irradiation plant.

The suggested code of practice, whilst it is unlikely to be universally enforceable as a statutory requirement, could act as a model of good practice not only amongst manufacturers using radiosterilization but also those using other forms of sterilization.

The International Atomic Energy Agency are to be congratulated on this presentation of the symposium at Vienna in a manner that will be appreciated by those interested in this subject who were unable to attend the symposium.

A. M. Coor

\section{FOR RADIATION WORKERS}

\section{Radiation Dosimetry}

Vol. 1: Fundamentals. Second edition. Edited by Frank H. Attix and William C. Roesch. Pp.xviii + 405. (Academic Press: New York and London, 1968.) 182s.

Autнобgr this book is called a second edition of that having the same title, edited in 1956 by Hine and Brownell, it is, in fact, a new book. Of the ten contributors to the eight chapters of this volume, only one, Rossi, contributed to the 1956 book, and then on a different topic.

There is substantial evidence of editorial coordination. Terminology and symbols are remarkably uniform for a book with so many contributors. There is little overlap of content between chapters, but considerable crossreferencing.

The editors contribute the first chapter on the basic concepts of dosimetry and include a brief account of the historical development of the subject. H. H. Rossi writes on microscopic energy distribution in irradiated matter, dealing both with linear energy transfer distributions and " $Y$ " and " $Z$ " distributions which are so much his own. R. D. Evans has a chapter on X-ray and $\gamma$-ray interactions which is packed with relevant formulae, and graphs and tables of interaction cross-sections and attenuation coefficients, while $\mathrm{H}$. Bichsel deals with charged particle interactions in a similar manner. W. C. Roesch draws together a great deal of otherwise scattered information in his chapter on the mathematical theory of radiation fields, using a list of more than sixty symbols in the process. J. A. Auxier, W. S. Snyder and T. D. Jones write on neutron interactions and penetration in tissue, devoting most of their chapter to the results of their extensive calculations of doses in a homogeneous anthropomorphic phantom. I. T. Myers has the shortest chapter on ionization in gases, liquids and solids, and the volume concludes with a chapter by T. E. Burlin on cavity-chamber theory which not only gives an excellent discussion of the theory as it relates to ionization chambers but also shows applications of the theory to liquid and solid dosimetric systems.

All the contributors have concentrated a large amount of information into their allotted space of about fifty pages. The book succeeds admirably in its declared primary intention of being a reference work for radiation workers and contains 470 literature citations. It has been long awaited and the arrival is no disappointment.

A few minor errors were detected but these only just reached double figures. The book is well produced and the figures are excellent, but for some reason the paper on which it is printed has been changed from that used for volume 2 which appeared about a year ago. The book deserves a wide sale.

J. R. Greening

\section{OBITUARIES}

\section{Dr Hugo Benioff}

THe first entry in the bibliography of Hugo Benioff, who died on February 29, is entitled simply "A New Vertical Seismograph". It appeared in the 1932 volume of the Bulletin of the Seismological Society. This paper might well have been subtitled "The beginning of a new era in instrumental seismology", for this was the eventual result of the Benioff variable reluctance seismograph. A few years later he described his linear strain seismograph, an instrument, which ultimately stimulated a whole new field of seismological research; that of long period surface waves and free oscillations of the Earth. Although best known for his contributions in seismological instrumentation, Benioff made profound contributions to the basic understanding of tectonies and earthquake mechanisms. In a classic series of papers between 1951 and 1955 he introduced the concept of instrumentally determined strain rebound, outlined the relation between aftershock sequences and stress relaxation, and then proceeded to apply these ideas to the study of global tectonies and deep crustal structure. In the course of this work he introduced many new procedures and new ideas and, although some were not confirmed by later work, the remarkable clarity of his physical intuition is attested to by the number of his hypotheses that continue to be valid.

One of his very early suggestions concerned the specification of ground movement during earthquakes for engineering purposes. He felt a special responsibility to help provide this kind of information at a time when little was known about destructive ground motion. His early definition of seismic destructiveness contains the essence of the procedures now used for measuring ground motion, and interpreting its effects on structures.

Benioff was very interested in the physics of musical instruments, and he made good use in geophysics of a number of analogies from this field. One cannot read his description of global strain release likened to the motion of a bowed violin string without recognizing that this man had great physical insight and sensitivity. The detection and measurement of the Earth's free vibrations was the last major experiment in which he participated, and it also had musical overtones. For a number of years he had been interested in measuring the fundamental vibration of the Earth, thought, at that time, to have a period of about $1 \mathrm{~h}$. For this purpose he set up strain seismographs with maximum sensitivity adjusted to this period. In 1952, after the Kamchatka earthquake, he observed several cycles of an oscillation with a period of $57 \mathrm{~min}$. Although it was later shown that this could not have been an elastic vibration of the Earth because it was too highly damped, he greatly stimulated other geophysicists, which brought about a large amount of theoretical and computation work resulting in a new branch of geophysies, terrestrial spectroscopy. When the Chilean earthquake of 1960 occurred, the stage was set, and the complete spectrum of Earth vibrations was clearly visible for the first time.

During his life Benioff received many honours; among these were election to the US National Academy of Sciences in 1953, and the award of the Day Medal of the American Geophysical Union. What he left to the world seismological community was a new generation of seismic instruments, and a published record of ideas and data that provided the starting point for many in the following generation of seismologists. 